\title{
Accuracy of Multidetector-Row Computed Tomography in the Preoperative Diagnosis of Lymph Node Metastasis in Patients with Gastric Cancer
}

\author{
Keisuke Kubota ${ }^{a}$ Akihiro Suzuki $^{a}$ Hironori Shiozaki ${ }^{a}$ Takeshi Wada ${ }^{b}$

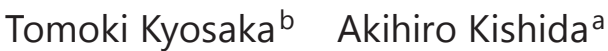 \\ Departments of a Gastroenterological Surgery and ${ }^{b}$ Radiology, St. Luke's International \\ Hospital, Tokyo, Japan
}

\author{
Keywords \\ Computed tomography · Gastric cancer · Lymph node metastasis
}

\begin{abstract}
Background/Aims: Preoperative lymph node staging in gastric cancer patients is important. The aim of this study was to assess the diagnostic accuracy of computed tomography (CT) in assessing lymph nodes in patients with gastric cancer. Methods: A total of 56 patients had undergone standardized gastric resection with lymphadenectomy between October 2013 and June 2015 were reviewed retrospectively. The short axis diameter of the largest lymph node per station was recorded when reviewing the preoperative CT images. Diagnostic accuracy was calculated by comparing CT with histopathological findings. Results: In 518 stations dissected at surgery, 56 included lymph nodes with metastasis. Among them, lymph nodes were visualized on preoperative CT in 26 stations. No lymph node was detected in 382 stations among 462 infiltration-negative stations. The cutoff of $12 \mathrm{~mm}$ had the highest accuracy rate of 0.896. Conclusion: The accuracy of CT in the preoperative diagnosis of lymph node metastasis in patients with gastric cancer remains poor. Therefore, surgeons should pay attention to the visibility of lymph nodes on CT. Detection of lymph nodes on CT can be utilized for a more accurate diagnosis such as fine-needle aspiration biopsy.
\end{abstract}

(C) 2017 S. Karger AG, Basel 


\section{Introduction}

Accurate preoperative evaluation, especially for lymph node metastasis, is important for determining the therapeutic options of patients with gastric cancer. The National Comprehensive Cancer Network guidelines [1] state that perioperative chemotherapy or preoperative chemoradiation is the preferred approach for clinical stage II (T2-3/N+ or T4) or more advanced gastric cancers. The Japanese gastric cancer treatment guidelines 2010 (ver. 3) [2] recommend a D1 lymphadenectomy for cT1N0 tumors and a D2 lymphadenectomy for potentially curable T2-4 tumors as well as cT1N+tumors. The revised Japanese Classification of Gastric Carcinoma [3] and the new TNM staging system [4] require the selective identification of single lymph nodes to differentiate between clinical $\mathrm{N}$ stages, thus further complicating evaluation.

At our institute, the most commonly used diagnostic method for lymph node staging of gastric cancer patients is 64-slice multidetector-row computed tomography (CT). So far, lymph nodes $>10 \mathrm{~mm}$ in size are considered to be metastasis-positive in usual clinical settings [5]. Recently, since the adaptation of laparoscopic gastrectomy has been expanded and adapted for cT2-3N0 tumors, preoperative lymph node staging in gastric cancer patients has become more important.

The aim of this study was to assess the preoperative diagnostic accuracy of lymph node involvement in patients with gastric cancer using $\mathrm{CT}$, and to define standard diagnostic criteria.

\section{Methods}

From October 2013 to June 2015, 80 consecutive patients underwent surgery for gastric cancer at St. Luke's International Hospital. Of those, patients with residual stomach cancer, those who underwent bypass surgery or probe laparotomy alone, and those who were treated with neoadjuvant chemotherapy were excluded. The present study included the remaining 56 patients who underwent standardized gastric resection with lymphadenectomy and who were reviewed retrospectively. All patients had been examined by CT before the surgery, and all tumors had been histopathologically diagnosed as adenocarcinomas of the stomach. The patients had undergone distal/total/proximal gastrectomy with standard lymph node dissection. The type of gastrectomy had been decided after considering the tumor location and progression according to the Japanese gastric cancer treatment guidelines 2010 (ver. 3) [2].

Two experienced radiologists (T.W., T.K.) who were blinded to the surgical or histopathological findings reviewed the axial CT images with a section thickness of $5 \mathrm{~mm}$. The short axis diameter of the largest lymph node per station was measured and recorded. Some typical CT scan images are shown in Figure 1. The locations of the lymph nodes were based on the revised Japanese Classification of Gastric Carcinoma [3]. Diagnostic accuracy was calculated by comparing the CT scan with the histopathological findings.

First, we assessed the preoperative diagnostic accuracy of lymph node involvement per station and defined the standard diagnostic criteria. Although we usually use a cutoff value of $10 \mathrm{~mm}$ for the diagnosis of lymph node metastasis of gastric cancer, we evaluated the accuracy rate using various cutoff values in this study. Second, the diagnostic accuracy of lymph node involvement per patient (N0 or N+) was confirmed. Third, the distribution of lymph nodes visualized on CT and those with infiltration was investigated, and the diagnostic accuracy of lymph node metastasis in each station was confirmed.

The $t$ test was used for comparisons of continuous data between two groups. A $p$ value $<0.05$ was considered significant. Statistical analysis was performed using the SPSS statistical package, version 15.0 (SPSS Inc., Chicago, IL, USA).

Our study had approval of the institutional ethics review board, and written informed consent for preoperative staging with CT and surgery had been obtained from all patients. 
Gastro

Intestinal

Tumors

Fig. 1. Some representative CT scan images of lymph nodes of gastric cancer patients. a Enlarged lymph nodes of a patient with histopathologically infiltration-positive lymph nodes (arrows). The short axis diameter of the largest lymph node was $19 \mathrm{~mm}$. b In another patient with histopathologically infiltration-positive lymph nodes, only tiny lymph nodes (maximum $5 \mathrm{~mm}$ ) were visualized on preoperative CT scan (arrows). c In a patient with no histopathologically infiltration-positive lymph nodes, some large lymph nodes (11 mm) were visualized on CT scan (arrows).

\begin{tabular}{l|l}
\hline Gastrointest Tumors 2016;3:163-170 \\
\hline DOI: 10.1159/000454923 & $\begin{array}{l}\text { @ 2017 S. Karger AG, Basel } \\
\text { www.karger.com/gat }\end{array}$ \\
\hline
\end{tabular}

Kubota et al.: Accuracy of Multidetector-Row Computed Tomography in the Preoperative Diagnosis of Lymph Node Metastasis in Patients with Gastric Cancer
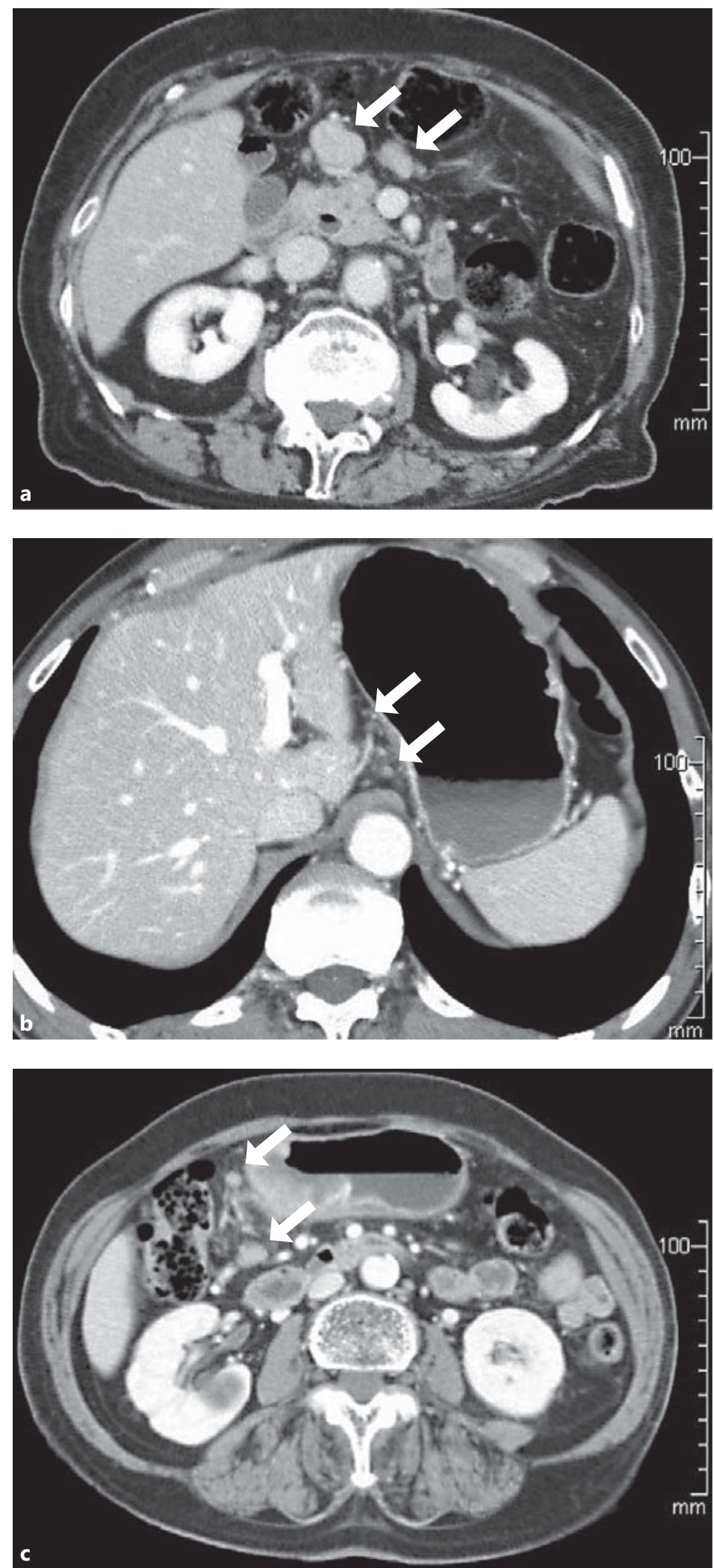
Table 1. Patient characteristics

Kubota et al.: Accuracy of Multidetector-Row Computed Tomography in the Preoperative Diagnosis of Lymph Node Metastasis in Patients with Gastric Cancer

\begin{tabular}{lc}
\hline Median age, years (range) & $68(51-93)$ \\
Gender & 35 \\
Male & 21 \\
Female & \\
Type of gastrectomy & 42 \\
$\quad$ Distal & 9 \\
Total & 5 \\
$\quad$ Proximal & \\
pT & 34 \\
T1 & 8 \\
T2 & 7 \\
T3 & 7 \\
T4 & \\
pN & 35 \\
N0 & 11 \\
N1 & 1 \\
N2 & 9 \\
N3 & \\
p stage & 36 \\
I & 10 \\
II & 5 \\
III & 5 \\
IV & \\
lymph nodes (IQR) & $28(20-39)$ \\
\hline
\end{tabular}

$\mathrm{IQR}$, interquartile range.

Table 2. Lymph node appearance on CT and correlation with histopathological findings

\begin{tabular}{llc}
\hline & \multicolumn{2}{l}{ Infiltration in dissected lymph node station } \\
\cline { 3 - 3 } & positive $(n=56)$ & negative $(n=462)$ \\
\hline Number of stations on CT & & 80 \\
$\quad$ With visible lymph node & 26 & 382 \\
$\quad$ Without visible lymph node & 30 & 5.3 \\
Size of visible lymph nodes, mm & & $1.0-11$ \\
$\quad$ Median & 6.5 & $1.4-19$ \\
$\quad$ Range & & \\
\hline
\end{tabular}

\section{Results}

The characteristics of the 56 patients are summarized in Table 1. Histopathological lymph node metastases were present in 21 patients (37.5\%). At surgery, 1,661 lymph nodes (median 28 lymph nodes per patient) were dissected, of which 152 (9.2\%) were histopathologically infiltrated.

When analyzed in terms of lymph node station, 518 stations were dissected at surgery, of which $56(10.8 \%)$ included lymph node(s) with metastasis (Table 2). Among these 56 infiltrated lymph node stations, lymph nodes were visualized on the preoperative CT in 26 stations. On the other hand, no lymph node was detected in 382 stations among 462 infiltration-negative lymph node stations. The size of the lymph nodes visualized on CT was 


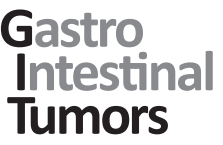

Table 3. Correlations between radiological size and histopathological station involvement: sensitivity, specificity, predictive values, and accuracy in accordance with each cutoff

\begin{tabular}{|c|c|c|c|c|c|}
\hline \multicolumn{6}{|c|}{ Gastrointest Tumors 2016;3:163-170 } \\
\hline \multicolumn{3}{|c|}{ DOI: $10.1159 / 000454923$} & \multicolumn{3}{|c|}{$\begin{array}{l}\text { (c) } 2017 \text { S. Karger AG, Basel } \\
\text { www.karger.com/gat }\end{array}$} \\
\hline \multicolumn{6}{|c|}{$\begin{array}{l}\text { Kubota et al.: Accuracy of Multidetector-Row Computed Tomography in the } \\
\text { Preoperative Diagnosis of Lymph Node Metastasis in Patients with Gastric Cancer }\end{array}$} \\
\hline Cutoff, mm & Sensitivity & Specificity & PPV & NPV & Accuracy \\
\hline 12 & 0.036 & 1.000 & 1.000 & 0.895 & 0.896 \\
\hline 10 & 0.054 & 0.994 & 0.500 & 0.896 & 0.892 \\
\hline 8 & 0.179 & 0.970 & 0.417 & 0.907 & 0.884 \\
\hline 5 & 0.357 & 0.894 & 0.290 & 0.920 & 0.836 \\
\hline 1 & 0.464 & 0.827 & 0.245 & 0.927 & 0.788 \\
\hline
\end{tabular}

PPV, positive predictive value; NPV, negative predictive value.

\begin{tabular}{rlllll}
\hline Cutoff, mm & Sensitivity & Specificity & PPV & NPV & Accuracy \\
\hline 12 & 0.095 & 1.000 & 1.000 & 0.648 & 0.661 \\
10 & 0.143 & 0.886 & 0.429 & 0.633 & 0.607 \\
8 & 0.381 & 0.743 & 0.471 & 0.667 & 0.607 \\
5 & 0.714 & 0.257 & 0.366 & 0.600 & 0.429 \\
1 & 0.905 & 0.171 & 0.396 & 0.750 & 0.446 \\
\hline
\end{tabular}

PPV, positive predictive value; NPV, negative predictive value.
Table 4. Correlations between radiological size and histopathological lymph node involvement per patient $(\mathrm{N}+$ or N0): sensitivity, specificity, predictive values, and accuracy in accordance with each cutoff 


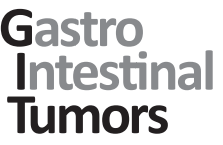

Table 5. Lymph node detection by CT in all the stations

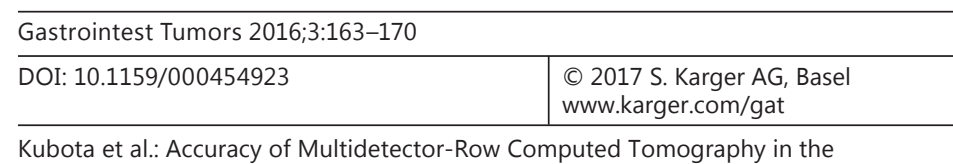

Kubota et al.: Accuracy of Multidetector-Row Computed Tomography in the Preoperative Diagnosis of Lymph Node Metastasis in Patients with Gastric Cancer

\begin{tabular}{|c|c|c|c|}
\hline \multirow[t]{2}{*}{ Station ${ }^{1}$} & \multicolumn{2}{|c|}{ With visible LN on CT } & \multirow{2}{*}{$\begin{array}{l}\text { With } \\
\text { infiltration, } \\
n\end{array}$} \\
\hline & $n$ & $\begin{array}{l}\text { median size, } \\
\text { mm }\end{array}$ & \\
\hline \multicolumn{4}{|c|}{ Perigastric } \\
\hline \#1 & 19 & 6.2 & 4 \\
\hline$\# 2$ & 0 & - & 0 \\
\hline \#3 & 25 & 5.7 & 12 \\
\hline$\# 4$ sa & 1 & 3.0 & 0 \\
\hline$\# 4 \mathrm{sb}$ & 2 & 4.0 & 0 \\
\hline$\# 4 \mathrm{~d}$ & 20 & 4.7 & 11 \\
\hline \#5 & 0 & - & 3 \\
\hline \#6 & 12 & 4.9 & 10 \\
\hline \multicolumn{4}{|c|}{ Intermediate } \\
\hline \#7 & 6 & 5.7 & 4 \\
\hline \#8а & 19 & 5.3 & 5 \\
\hline \#9 & 2 & 9.3 & 3 \\
\hline \#10 & 0 & - & 0 \\
\hline \#11 & 0 & - & 1 \\
\hline$\# 12 \mathrm{a}$ & 25 & 4.4 & 2 \\
\hline \multicolumn{4}{|l|}{ Distant } \\
\hline \#13 & 6 & 4.5 & 0 \\
\hline$\# 14 \mathrm{v}$ & 1 & 6.3 & 1 \\
\hline \#16 & 4 & 5.4 & 0 \\
\hline
\end{tabular}

LN, lymph node. ${ }^{1}$ According to the Japanese Classification of Gastric Carcinoma [3]. \#1, right paracardial; \#2, left paracardial; \#3, lesser curvature; \#4sa, short gastric arteries; \#4sb, left gastroepiploic artery; \#4d, greater curvature; \#5, suprapyloric; \#6, infrapyloric; \#7, left gastric artery; \#8a, common hepatic artery; \#9, celiac artery; \#10, splenic hilar; \#11, splenic artery; \#12a, proper hepatic artery; \#13, posterior pancreatic head; \#14v, superior mesenteric vein; \#16, paraaortic.

widely used standard diagnostic tool, it is not considered the gold standard technique for $\mathrm{N}$ staging [6].

To improve the accuracy of the preoperative diagnosis of lymph node metastasis in gastric cancer patients, various methods have been reported. Although lymph nodes $>8 \mathrm{~mm}$ in the short axis diameter are generally considered to be positive, different criteria have been proposed for assessing nodal status, including a size $>6 \mathrm{~mm}$ plus round shape, a size $>8 \mathrm{~mm}$ irrespective of axis, or a simple radiological detection of node [7, 8]. A modified analytical technique on CT includes size and other characteristics such as marked enhancement, necrosis, shape, and fat content $[9,10]$. The accuracy in detecting lymph node metastasis with the conventional diagnostic tool is only around $60-80 \%$, even when these other techniques are used [11]. In order to confirm the accuracy of preoperative imaging diagnosis for stage III gastric cancer, a validity study (JCOG 1302-A, "PRIMA-GC study") is now ongoing in Japan.

Regarding other modalities, Kwee and Kwee reviewed the diagnostic accuracy of preoperative $\mathrm{N}$ staging by comparing endoscopic ultrasound, magnetic resonance imaging, positron emission tomography-CT, and CT [12]. In their study, the accuracy of $\mathrm{N}$ status diagnosis ranged from 40 to $90 \%$. Although endoscopic ultrasound showed an accuracy similar to that of CT, the ultrasound is not objective and presents difficulty in evaluating lymph nodes that are located farther from the gastric wall. The diagnostic accuracy of magnetic resonance imaging is also poor. Low accuracy was also reported in positron emission tomography-CT 
studies due to the low sensitivity in detecting lymph node metastasis with fluorodeoxyglucose.

The limitation of our study was the small number of patients. However, if we analyze a larger number, the result may not change because the ability of CT to detect lymph nodes is very poor. Moreover, lymph node metastases were evaluated in each region, not for each lymph node individually, because it is hard to match the lymph nodes dissected during surgery with those evaluated on CT. The most important point in our study for clinical use may be the accurate diagnosis of clinical $\mathrm{N}$ status, not of individual nodal status. However, the diagnosis of lymph node metastases per patient (N0 or $\mathrm{N}+$ ) was difficult to do on CT in this study.

Additional findings obtained from the analysis per station in our study were as follows: (1) In stations \#5 (suprapyloric) and \#11 (splenic artery), there were some lymph node metastases, although preoperative CT could not detect them. Therefore, surgeons should pay special attention to cases like these. (2) Many swelled lymph nodes were visible on CT in stations \#8a (common hepatic artery), \#12a (proper hepatic artery), and \#13 (posterior pancreatic head), regardless of the presence of metastasis. There is a possibility of overtreatment with preoperative chemoradiotherapy or extended lymph node dissection if they are performed on the basis of the findings of \#8a, \#12a, or \#13 lymph node swelling. Since lymph nodes are visible on CT, we can introduce endoscopic ultrasound-fine-needle aspiration biopsy for a more accurate diagnosis.

In conclusion, the accuracy of CT in the preoperative diagnosis of lymph node metastasis in patients with gastric cancer remains poor. Since lymph node metastases present at a certain frequency in gastric cancer patients, systematic dissection of lymph nodes must be performed at surgery, even when no lymph nodes are detected on preoperative CT. Gastric surgeons as well as radiologists should keep in mind that visible lymph nodes on CT are not necessarily metastatic and that lymph node detection on CT can be utilized to introduce endoscopic ultrasound-fine-needle aspiration biopsy.

\section{Disclosure Statement}

The authors have no conflicts of interest to declare in association with this study.

\section{References}

1 Ajani JA, Bentrem DJ, Besh S, D'Amico TA, Das P, Denlinger C, Fakih MG, Fuchs CS, Gerdes H, Glasgow RE, Hayman JA, Hofstetter WL, Ilson DH, Keswani RN, Kleinberg LR, Korn WM, Lockhart AC, Meredith K, Mulcahy MF, Orringer MB, Posey JA, Sasson AR, Scott WJ, Strong VE, Varghese TK Jr, Warren G, Washington MK, Willett C, Wright CD, McMillian NR, Sundar H; National Comprehensive Cancer Network: Gastric cancer, version 2.2013: featured updates to the NCCN Guidelines. J Natl Compr Canc Netw 2013;11:531-546.

2 Japanese Gastric Cancer Association: Japanese gastric cancer treatment guidelines 2010 (ver. 3). Gastric Cancer 2011:14:113-123.

3 Japanese Gastric Cancer Association: Japanese Classification of Gastric Carcinoma: 3rd English edition. Gastric Cancer 2011;14:101-112.

4 Sobin LH, Gospodarowics MK, Wittekind C (eds): TNM Classification of Malignant Tumours, ed 7. New York, Wiley-Blackwell, 2009.

5 Park SR, Kim MJ, Ryu KW, Lee JH, Nam BH, Choi U, Kim YW: Prognostic value of preoperative clinical staging assessed by computed tomography in resectable gastric cancer patients. Ann Surg 2010;251:428-435.

6 Saito T, Kurokawa Y, Takiguchi S, Miyazaki Y, Takahashi T, Yamasaki M, Miyata H, Nakajima K, Mori M, Doki Y: Accuracy of multidetector-row CT in diagnosing lymph node metastasis in patients with gastric cancer. Eur Radiol 2015;25:368-374.

7 Morgagni P, Petrella E, Basile B, Mami A, Soro A, Gardini A, Calzolari F, Garcea D, Bertocco M: Preoperative multidetector-row computed tomography scan staging for lymphatic gastric cancer spread. World J Surg Oncol 2012;10:197. 
8 Habermann CR, Weiss F, Riecken R, Honarpisheh H, Bohnacker S, Staedtler C, Dieckmann C, Schoder V, Adam G: Preoperative staging of gastric adenocarcinoma: comparison of helical CT and endoscopic US. Radiology 2004;230:465-471.

9 Kawaguchi T, Komatsu S, Ichikawa D, Okamoto K, Shiozaki A, Fujiwara H, Murayama Y, Kuriu Y, Ikoma H, Nakanishi M, Ochiai T, Kokuba Y, Nishimura T, Otsuji E: Nodal counts on MDCT as a surrogate marker for surgical curability in gastric cancer. Ann Surg Oncol 2012;19:2465-2470.

10 Hasegawa S, Yoshikawa T, Shirai J, Fujikawa H, Cho H, Doiuchi T, Yoshida T, Sato T, Oshima T, Yukawa N, Rino Y, Masuda M, Tsuburaya A: A prospective validation study to diagnose serosal invasion and nodal metastases of gastric cancer by multidetector-row CT. Ann Surg Oncol 2013;20:2016-2022.

11 Kim YN, Choi D, Kim SH, Kim MJ, Lee SJ, Lee WJ, Kim S, Kim JJ: Gastric cancer staging at isotropic MDCT including coronal and sagittal MPR images: endoscopically diagnosed early vs. advanced gastric cancer. Abdom Imaging 2009;34:26-34.

12 Kwee RM, Kwee TC: Imaging in assessing lymph node status in gastric cancer. Gastric Cancer 2009;12:6-22. 